\title{
Biopolymer Films and Coatings in Packaging Applications-A Review of Recent Developments
}

\author{
Jari Vartiainen, Mika Vähä-Nissi, Ali Harlin \\ VTT Technical Research Centre of Finland, Espoo, Finland \\ Email: jari.vartiainen@vtt.fi
}

Received 30 May 2014; revised 3 July 2014; accepted 18 July 2014

Copyright (C) 2014 by authors and Scientific Research Publishing Inc.

This work is licensed under the Creative Commons Attribution International License (CC BY). http://creativecommons.org/licenses/by/4.0/

cC) (7) Open Access

\begin{abstract}
This review covers the recent developments in the field of biobased packaging materials. Special emphasis is placed on the barrier properties, which are crucial in terms of food packaging. The state-of-the-art of several biopolymers including pectin, starch, chitosan, xylan, galactoglucomannan, lignin and cellulose nanofibrils is discussed. As in most cases the packaging related properties of single layer biopolymer films are inadequate, the thin film coatings, such as sol-gel and ALD (atomic layer deposition), as well as the multilayer coatings are also briefly touched.
\end{abstract}

\section{Keywords}

\section{Biopolymers, Packaging, Films and Coatings, Barrier Properties}

\section{Introduction}

Biobased plastics and biopolymers have been widely studied in recent years. Replacing the oil-based packaging materials with biobased films and containers might give not only a competitive advantage due to more sustainable and greener image, but also some improved technical properties. Sustainable economy utilizes mainly biomass derived raw materials for high-volume applications, such as packaging [1]. Special attention should be paid to barrier properties which are extremely important especially for biobased food packaging materials. Moisture resistance with hydrophilic polymers is in many cases inadequate, thus excessive water vapour transmission through packaging dilutes the quality of foods resulting in shorter shelf-lives, increased costs and eventually more waste. Typical and widely used bioplastics include polylactic acid (PLA), polyhydroxyalkanoates (PHA), polyhydroxybutyrates (PHB), cellophane etc. As with all bioplastics, the barrier properties of for example PLA films can be improved by adding fillers such as nanoclays [2]. Among the bioplastics, polyglycolic acid 
(PGA) has excellent barrier properties thus it's one of the most promising new commercially available barrier polymers. Its precursor, glycolic acid, can now be produced via a natural metabolic route, the glyoxylate cycle [3].

This review describes some of the most studied biopolymers which may have a great importance in the future packaging business. The aim is to cover recent developments with respect to their potential for use in the sustainable and green packaging industry. Especially the barrier properties are identified as key issues for effective utilization of biobased materials [1].

\section{Biopolymers}

\subsection{Pectin}

Pectin is a structural heteropolysaccharide found in the primary cell walls of terrestrial plants such as sugar beet. From a physico-chemical point of view pectin is an anionic polyelectrolyte, thus ionic interactions have a great impact on its film forming properties and behaviour in dispersions with e.g. nanoclays. Pectin films plasticized with glycerol and further incorporated with nanoclay ( $>98 \%$ montmorillonite) were prepared by casting onto Petri dishes. In order to ensure the sufficient delamination and nanosized structure of the nanoclay platelets, the powder was first dispersed in water using either ultrasonic treatment or high pressure fluidization. The model surfaces were prepared by spin coating onto silica surfaces from the aqueous dispersions after both pre-treatments. The high pressure fluidizer treatment produced an even and more homogenous layer of parallelly oriented nanoclay platelets with the narrower size distribution as compared to particles after ultrasonic treatment. Thus, high pressure fluidizer treatment was selected as an efficient and easily up-scalable method to produce bio-hybrid nanocomposite dispersions. The resulting bio-hybrid nanocomposite films were totally greaseproof and also showed improved barrier properties against oxygen and water vapour (see Table 1, Table 2) [4]. Recently, pectin solutions have been roll-to-roll flexo-coated with semi-industrial pilot-line onto argon/nitrogen plasma-activated oriented polypropylene (OPP) film [5]. Plasma-activation was carried out inline to increase the surface energy of OPP film prior the coating with water-based pectin solution. Pectin was easily spread onto activated surface forming an even and smooth dry coating. Also other biopolymers, such as various starch grades and wood-derived xylan can be coated in a similar manner [6].

\subsection{Starch}

Starch films can be produced either by extrusion [7] [8] or casting [9] [10]. Plasticizers, such as glycerol, sorbitol or xylitol, are typically used for reducing the brittleness [11]. At low glycerol concentrations both strain and strength decreased but above $20 \%$ glycerol concentration the elongation reached larger values [12]. Effects of glycerol, sorbitol or xylitol on physical and mechanical properties of starch films were largest for glycerol and smallest for sorbitol. High contents of xylitol and sorbitol resulted in changes in physical and mechanical properties of films probably due to phase separation and crystallization [11]. Crystallization can be prevented by using binary polyol mixtures as plasticizers. Water sorption and water vapour permeability were lower for the films plasticized with xylitol-sorbitol mixture compared to the films plasticized with glycerol-xylitol and glycerol-sorbitol mixtures at constant plasticizer contents [13]. Oxygen permeability of the films was strongly dependent on the water content. At low humidity conditions the films are typically excellent barriers against oxygen transmission, but when the water content rises above $20 \%$ the barrier is mostly lost. The increased permeability was most likely due to increased polymer chain mobility, which facilitated the transport process [14]. Oxygen permeability of starch films can be decreased by using below $21 \%$ of sorbitol. This behaviour was related to changes in secondary relaxations which are hindered because of the connections established between starch and sorbitol, leading to decreased diffusion of oxygen molecules. For sorbitol contents above $21 \%$, oxygen permeability increased slightly. Water produced a classic plasticising effect (an increase of oxygen permeability), but at low sorbitol content this was only moderate due to the effect of sorbitol itself [15]. Compounding starch and glycerol with PCL (polycaprolactone) decreased the water vapour permeability of extruded films. Oxygen barrier properties however were impaired above 20\% PCL concentration [16].

\subsection{Chitosan}

Chitosan, the $\beta$-1-4-linked polymer of 2-amino-2-deoxy- $\beta$-d-glucose, is prepared by the $\mathrm{N}$-deacetylation of chi- 
Table 1. Oxygen permeability (OP) of biopolymer films.

\begin{tabular}{|c|c|c|c|}
\hline Film/coating & Conditions & $\mathrm{OP}\left(\mathrm{cc} \times \mu \mathrm{m} / \mathrm{m}^{2} /\right.$ day $)$ & Reference \\
\hline Pectin $^{\mathrm{a}}$ & $0 \% \mathrm{RH}, 23^{\circ} \mathrm{C}$ & 1000 & [4] \\
\hline Pectin $^{a}$ & $50 \% \mathrm{RH}, 23^{\circ} \mathrm{C}$ & 2400 & [4] \\
\hline Pectin $^{\mathrm{a}}$ & $80 \% \mathrm{RH}, 23^{\circ} \mathrm{C}$ & 32,000 & [4] \\
\hline Pectin $^{\mathrm{a}}+10 \%$ nanoclay & $0 \% \mathrm{RH}, 23^{\circ} \mathrm{C}$ & 600 & [4] \\
\hline Pectin $^{\mathrm{a}}+10 \%$ nanoclay & $50 \% \mathrm{RH}, 23^{\circ} \mathrm{C}$ & 1200 & [4] \\
\hline Pectin $^{a}+10 \%$ nanoclay & $80 \% \mathrm{RH}, 23^{\circ} \mathrm{C}$ & 18,300 & [4] \\
\hline Pectin $^{\mathrm{a}}+20 \%$ nanoclay & $0 \% \mathrm{RH}, 23^{\circ} \mathrm{C}$ & 400 & [4] \\
\hline Pectin $^{a}+20 \%$ nanoclay & $50 \% \mathrm{RH}, 23^{\circ} \mathrm{C}$ & 700 & [4] \\
\hline Pectin $^{\mathrm{a}}+20 \%$ nanoclay & $80 \% \mathrm{RH}, 23^{\circ} \mathrm{C}$ & 11,300 & [4] \\
\hline Pectin $^{\mathrm{a}}+30 \%$ nanoclay & $0 \% \mathrm{RH}, 23^{\circ} \mathrm{C}$ & 1400 & [4] \\
\hline Pectin $^{\mathrm{a}}+30 \%$ nanoclay & $50 \% \mathrm{RH}, 23^{\circ} \mathrm{C}$ & 2600 & [4] \\
\hline Pectin $^{\mathrm{a}}+30 \%$ nanoclay & $80 \% \mathrm{RH}, 23^{\circ} \mathrm{C}$ & 6400 & [4] \\
\hline Chitosan & $80 \% \mathrm{RH}, 23^{\circ} \mathrm{C}$ & 9800 & [18] \\
\hline Chitosan $+17 \%$ nanoclay & $80 \% \mathrm{RH}, 23^{\circ} \mathrm{C}$ & 4600 & [18] \\
\hline Chitosan $+50 \%$ nanoclay & $80 \% \mathrm{RH}, 23^{\circ} \mathrm{C}$ & 1900 & [18] \\
\hline Chitosan $+67 \%$ nanoclay & $80 \% \mathrm{RH}, 23^{\circ} \mathrm{C}$ & 1200 & [18] \\
\hline Chitosan crosslinked & $80 \% \mathrm{RH}, 23^{\circ} \mathrm{C}$ & 980 & [17] \\
\hline Chitosan crosslinked $+50 \%$ nanoclay & $80 \% \mathrm{RH}, 23^{\circ} \mathrm{C}$ & 280 & [17] \\
\hline $\mathrm{CNF}^{\mathrm{b}}$ bleached softwood & $80 \% \mathrm{RH}, 23^{\circ} \mathrm{C}$ & 5200 & {$[35]$} \\
\hline $\mathrm{CNF}^{\mathrm{b}}$ bleached hardwood & $80 \% \mathrm{RH}, 23^{\circ} \mathrm{C}$ & 2900 & [35] \\
\hline PVA-CNF & $0 \% \mathrm{RH}, 23^{\circ} \mathrm{C}$ & 0.5 & {$[36]$} \\
\hline PVA-CNF & $90 \% \mathrm{RH}, 23^{\circ} \mathrm{C}$ & 6790 & {$[36]$} \\
\hline PVA-CNF + 50\% nanoclay & $0 \% \mathrm{RH}, 23^{\circ} \mathrm{C}$ & 0.5 & {$[36]$} \\
\hline PVA-CNF + 50\% nanoclay & $90 \% \mathrm{RH}, 23^{\circ} \mathrm{C}$ & 190 & {$[36]$} \\
\hline CNF bleach birch pulp & $0 \% \mathrm{RH}, 23^{\circ} \mathrm{C}$ & $<1$ & [39] \\
\hline CNF bleach birch pulp & $50 \% \mathrm{RH}, 23^{\circ} \mathrm{C}$ & 30 & [39] \\
\hline CNF bleach birch pulp & $80 \% \mathrm{RH}, 23^{\circ} \mathrm{C}$ & 800 & [39] \\
\hline $\mathrm{CNF}^{\mathrm{a}}$ bleach birch pulp & $0 \% \mathrm{RH}, 23^{\circ} \mathrm{C}$ & 3 & [39] \\
\hline $\mathrm{CNF}^{\mathrm{a}}$ bleach birch pulp & $50 \% \mathrm{RH}, 23^{\circ} \mathrm{C}$ & 1700 & [39] \\
\hline $\mathrm{CNF}^{\mathrm{a}}$ bleach birch pulp & $80 \% \mathrm{RH}, 23^{\circ} \mathrm{C}$ & 15,500 & [39] \\
\hline CNF bleach birch pulp (heat treated) & $0 \% \mathrm{RH}, 23^{\circ} \mathrm{C}$ & $<1$ & [39] \\
\hline CNF bleach birch pulp (heat treated) & $50 \% \mathrm{RH}, 23^{\circ} \mathrm{C}$ & 2 & [39] \\
\hline CNF bleach birch pulp (heat treated) & $80 \% \mathrm{RH}, 23^{\circ} \mathrm{C}$ & 300 & [39] \\
\hline PVA & $90 \% \mathrm{RH}, 23^{\circ} \mathrm{C}$ & 45,000 & [48] \\
\hline CNF-PVA & $90 \% \mathrm{RH}, 23^{\circ} \mathrm{C}$ & 50,000 & [48] \\
\hline Epoxy-CNF-PVA & $90 \% \mathrm{RH}, 23^{\circ} \mathrm{C}$ & 48,000 & [48] \\
\hline
\end{tabular}

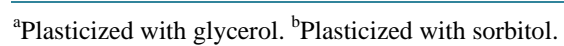


Table 2. Water vapour permeability (WVP) of biopolymer films at $23^{\circ} \mathrm{C}, 100 \% / 50 \%$ relative humidity.

\begin{tabular}{|c|c|c|}
\hline Film/coating & WVP $\left(g \times \mu \mathrm{m} / \mathrm{m}^{2} /\right.$ day $)$ & Reference \\
\hline Pectin $^{a}$ & 113,000 & [4] \\
\hline Pectin $^{\mathrm{a}}+10 \%$ nanoclay & 108,000 & [4] \\
\hline Pectin $^{a}+20 \%$ nanoclay & 102,000 & [4] \\
\hline Pectin $^{\mathrm{a}}+30 \%$ nanoclay & 87,000 & [4] \\
\hline Chitosan & 21,600 & [18] \\
\hline Chitosan $+17 \%$ nanoclay & 20,000 & [18] \\
\hline Chitosan $+50 \%$ nanoclay & 18,500 & [18] \\
\hline Chitosan $+67 \%$ nanoclay & 18,600 & [18] \\
\hline Chitosan crosslinked & 11,000 & [17] \\
\hline Chitosan crosslinked $+50 \%$ nanoclay & 7200 & [17] \\
\hline $\mathrm{CNF}^{\mathrm{b}}$ bleached softwood & 20,000 & [35] \\
\hline $\mathrm{CNF}^{\mathrm{b}}$ bleached hardwood & 24,000 & [35] \\
\hline PVA-CNF & 31,500 & [36] \\
\hline PVA-CNF + 50\% nanoclay & 17,500 & [36] \\
\hline CNF bleach birch pulp & 17,000 & [39] \\
\hline $\mathrm{CNF}^{\mathrm{a}}$ bleach birch pulp & 17,000 & [39] \\
\hline CNF bleach birch pulp (heat treated) & 15,000 & [39] \\
\hline PVA & 45,000 & [48] \\
\hline CNF-PVA & 50,000 & [48] \\
\hline Epoxy-CNF-PVA & 49,000 & [48] \\
\hline
\end{tabular}

${ }^{\mathrm{a}}$ Plasticized with glycerol. ${ }^{\mathrm{b}}$ Plasticized with sorbitol.

tin, the second most abundant natural biopolymer after cellulose. Chitosan is soluble in dilute aqueous acid solutions and has been widely studied due to its good film forming properties. Chitosan can be used as such in cast free standing films [17] [18] or it can be applied as a coating onto paper/board or plastic films [19]-[21]. Chitosan dissolved in $1 \%$ acetic acid was applied onto copy paper by lab-scale bar coater and dried at $105^{\circ} \mathrm{C}$. Chitosan coatings clearly improved both the gloss and oxygen barrier properties of paper. The gloss value in the machine direction was increased as a function of added chitosan. Oxygen transmission rate at $0 \%$ relative humidity was decreased from $>10,000 \mathrm{cc} / \mathrm{m}^{2} /$ day to $1.1 \mathrm{cc} / \mathrm{m}^{2} /$ day with $6.9 \mathrm{~g} / \mathrm{m}^{2}$ chitosan coating. In addition, the effects on the mechanical properties were positive, but not significant. The water vapour permeability of the paper increased as a result of the chitosan coating [19]. Chitosan can also be immobilized onto $\mathrm{NH}_{3}$ - or $\mathrm{CO}_{2}$-plasma activated polypropylene films by exploiting either carbodiimide or glutaraldehyde chemistries. Chitosan coatings made film surfaces hydrophilic and prevented clearly both oxygen, carbon dioxide and ethylene transmission. Oxygen transmission rate at $0 \% \mathrm{RH}$ decreased from $1500 \mathrm{cc} / \mathrm{m}^{2} /$ day to $27 \mathrm{cc} / \mathrm{m}^{2} /$ day with $1.8 \mathrm{~g} / \mathrm{m}^{2}$ chitosan coating [20]. Barrier properties can be further improved by using nanoclays incorporated into chitosan. Nanoclay was mixed with chitosan and further dispersed using ultrasonic treatment and coatings were applied onto plasma-activated LDPE-coated paper by lab-scale coater. Also free-standing films were cast onto Petri dishes. Bio-hybrid nanocomposite films and multilayer coatings had improved barrier properties against oxygen, water vapour, grease, and UV-light transmission. Oxygen transmission was significantly reduced under all humidity conditions. In dry conditions, $>99 \%$ reduction and at $80 \%$ relative humidity almost $75 \%$ reduction in oxygen transmission rates was obtained. Hydrophilic chitosan was lacking the capability of preventing water vapour transmission, thus total barrier effect of nanoclay containing films was not more than $15 \%$ as compared to pure 
chitosan (see Table 1, Table 2) [18].

\subsection{Xylan}

Xylan is alkali extracted from kraft hardwood pulp. It is almost as ubiquitous as cellulose in plant cell walls and contains predominantly $\beta$-D-xylose units linked as in cellulose. Xylan as such is not suitable for film formation due to its high internal cohesion, which results in fragile and fragmented films. Thus, xylan needs to be plasticized externally or internally. It can be further hydroxypropylated resulting in water soluble derivative with improved film forming properties. The inner plasticization with hydroxypropyl groups can be combined with external plasticization using glycerol or sorbitol. The biodegradability, high degree of biobased raw materials, and non-food origin of hydroxypropylatedxylan (HPX) coatings and films make them an interesting option for food packaging [22]. Coatings of aqueous HPX solutions containing glycerol and sorbitol were applied with a lab-scale bar coater onto a pigment coated board. $5 \%$ citric acid was used as a biobased crosslinker to enhance the barrier properties. A crosslinked HPX coating demonstrated a good grease and mineral oil barrier as well as low oxygen transmission rate of $200 \mathrm{~cm}^{3} / \mathrm{m}^{2} /$ day at $50 \%$ relative humidity. Water vapour permeabilities of the xylan coatings were slightly below that measured for the commercial biopolymer, polylactic acid (PLA), coating [23]. Also the free standing HPX films plasticized with $10 \%$ and $20 \%$ of sorbitol had relatively low oxygen permeabilities at $<75 \%$ relative humidity [24]. In addition, fatty acid esters of hemicelluloses and cellulose have been coated successfully on paper/board. The coatings were hydrophobic and provided good grease and moisture barrier properties. The best water and water vapour barrier was achieved with the cellulose derivatives esterified with the longest fatty acid. Benzyl ether derivatives of birch xylan with varying degree of substitution have recently been prepared. These derivatives are also hydrophobic and thermoplastic capable of forming free standing films from organic solvents [25]-[27]. The paper sheets prepared from the esterified cellulose fibers showed high hydrophobicity [28]. The barrier properties of xylan may be further improved through nanoclay reinforcement in aqueous medium. The nanoclay dispersions were mixed with the plasticized (glycerol) xylan, resulting in homogeneous and viscous coating solutions. Xylan-nanoclay dispersion was further coated onto paper by lab-scale bar coater. The coatings significantly enhanced water vapour barrier properties [29].

\subsection{Galactoglucomannan}

The main hemicellulose in softwood is O-acetyl-galactoglucomannan (AcGGM). AcGGM has a main chain of

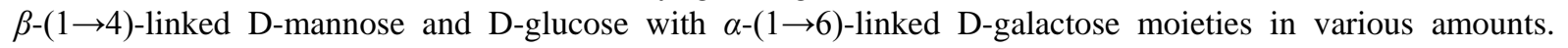
AcGGM is soluble in water and organic solvents. The solubility properties can be attributed to a high degree of acetylation in combination with a low molecular weight. Cast films have been produced with plasticizers such as glycerol, sorbitol and xylitol, and the biobased polymers such as alginate and carboxymethylcellulose (CMC). The addition of plasticizers resulted in increased film flexibility and moisture sensitivity. With other biobased polymers, the mechanical strength and resistance towards humidity increased [30].

\subsection{Lignin}

Lignin is one of the most abundant natural polymers, together with cellulose and hemicellulose. Softwood lignin has been esterified with tall oil fatty acid (TOFA) and applied with a lab-scale bar coater onto paperboard. The WVTR of the paperboard was reduced by $70 \%$ with a TOFA lignin ester double coating of $3.9 \mathrm{~g} / \mathrm{m}^{2}$. Also a decrease in oxygen transmission was observed for the TOFA lignin ester as well as the TOFA coated paperboard samples. The coating material did not affect the tensile strength of the paperboard [31]. Esterification with palmitic and lauric acid chloride resulted in coatings with improved moisture barrier properties. A significant decrease in water vapour transmission was observed, for example, $40 \mathrm{~g} / \mathrm{m}^{2} /$ day for a paperboard coated with $10.4 \mathrm{~g} / \mathrm{m}^{2}$ hardwood kraft lignin palmitate. For all paperboard samples coated with lignin esters, a significant decrease in oxygen transmission rate was observed [32].

\subsection{CNF}

Cellulose nanofibrils (CNF), also referred to as nanocellulose are typically generated by mechanical grinding or high pressure fluidisation. CNF consists of very thin $(\sim 20 \mathrm{~nm})$ and long (several $\mu \mathrm{m})$ fibrils and in low concentrations of $<2 \%$, it forms a gel-like, transparent material which can be used for producing biodegradable and en- 
vironmentally safe, homogenous and dense films [33] [34]. CNF can be produced from various raw materials. Recently CNF films have been prepared from banana, sugar beet, hemp, softwood and hardwood pulps. Films were plasticized with $30 \%$ of sorbitol and they had some promising technical properties including grease proofness and high barrier against oxygen transmission especially at dry conditions (see Table 1) [35]. Lab-scale nanocomposite films of CNF, polyvinyl alcohol (PVA), and montmorillonite nanoclay were prepared via casting onto Petri-dishes. PVA matrices were further crosslinked with polyacrylic acid. Nanoclay provided an improved barrier properties against both water and oxygen transmission through the films. Permeability and adsorption were further reduced by crosslinking, while oxygen barrier properties were remarkably enhanced also at high humidity conditions (see Table 1) [36]. Recently, a semi-industrial roll-to-roll pilot-line has been utilized in production of high quality CNF films with excellent technical properties. The developed method is easily up-scalable and brings CNF film production a step closer to commercialization [37].

\section{Modification towards Better Properties}

In addition to incorporation of nanoclays, the barrier properties of biopolymers may be improved by chemical and physical crosslinking, or with surface treatments, such as grafting and coating. For example, the plasma or heat induced oxidation/degradation can promote chain scission and crosslinking on surfaces. By heating the coatings over melting point and cooling them slowly back to room temperature, the coating density, morphology, crystallinity and spherulite size can be modified towards better barrier properties [38]. Heat treatment at $200^{\circ} \mathrm{C}$ induced irreversible hydrogen bonding to cellulose which improved both barrier properties and mechanical strength of CNF films (see Table 1, Table 2) [39]. Chitosan-nanoclay bio-hybrid films have been successfully crosslinked with glutaraldehyde, genipin and glyoxal. Moisture sensitivity of films decreased as a result of crosslinking which led to improved barrier properties against water vapour and oxygen transmission at high humidity (see Table 1, Table 2) [17]. Enzymatically crosslinked casein coatings have been applied onto corona-treated PE film and board for improving the packaging related surface properties [40]. Recently, the aqueous crosslinked PLA dispersions were coated onto board at pilot-scale [6] [41]. For decreasing the moisture sensitivity, the hydrophobic softwood galactoglucomannan films have been prepared by benzylation. Also styrene grafting of films based on unmodified AcGGM by plasma and vapour-phase treatments have been performed. Finally, lamination of an unmodified AcGGM film with benzylated AcGGM was also investigated in terms of water tolerance and oxygen permeability. Both surface grafting and especially the lamination method decreased the moisture sensitivity and improved the barrier properties [42]. Recently, the enzymatically treated cellulose has been dissolved in a $\mathrm{NaOH} / \mathrm{ZnO}$ solvent system and mixed together with poly(ethylene-co-acrylic acid) or poly(acrylamide-co-acrylic acid) polymers, in order to improve the properties and prepare homogeneous cellulose-based blends for films and coatings. Dissolved cellulose/acrylic acid copolymer-based blends performed well as coating materials on paperboard. All blends showed a good resistance against grease with $2 \mu \mathrm{m}$ coating layer. In addition, cellulose/poly(ethylene-co-acrylic acid) coating showed improved water vapour and oxygen barrier properties as compared with neat dissolved cellulose coated paperboard [43]. Plasma-activated biaxially oriented polypropylene (BOPP) films and paper substrates have been coated with hydrophobically modified chitosan solutions. Enzyme-catalysed grafting of octyl gallate and dodecyl gallate to amino groups of chitosan increased surface hydrophobicity and improved oxygen barrier properties [21]. Also CNF films have been enzymatically grafted with dodecyl gallate resulting in less hydrophilic coatings on paper [44]. An easy method to improve hydrophobicity and oxygen barrier properties of CNF films at very high humidity is to use simple paraffin wax coating. The films were dipped into the melted wax and the excess wax was removed from the surface resulting in both improved water vapour and oxygen barrier as well as the high surface hydrophobicity [45]. Multilayer coatings of CNF and shellac have been deposited on the fibre based substrates using a lab-scale bar coater or a spray coating technique. Multi-layer system with CNF as a first layer and shellac as the top layer decreased both oxygen and water vapour transmission rates [46]. Hydrophobization of the CNF film surface can also be achieved by chemical modification through silylation chemistry. After modification, the wettability of the film surface was drastically reduced. The hydrophobicity of the film did not only occur on the surface, but it was extended through the whole film, as verified by its significantly higher dimensional stability when submerged in water [47]. Chemically surface-modified CNF has been used as reinforcement in cast polyvinyl alcohol (PVA) films. CNF was allylated and further epoxidised with hydrogen peroxide. The addition of $1 \mathrm{wt} \%$ epoxy-CNF enhanced the modulus, strength and crystallinity of the pure PVA film [48]. In addition, the modified 
O-acetyl galactoglucomannans (GGM) have been recently utilized in modification of CNF film surfaces. Four GGM-block-structured, amphiphilic derivatives were synthesized using either fatty acids or polydimethylsiloxane as hydrophobic tails. It was found that the hydrophobic tails did not hinder adsorption of the GGM derivatives to cellulose, which was concluded to be due to the presence of the native GGM-block with high affinity to cellulose. CNF films were further prepared and coated with the GGM derivatives, but only slight improvements in oxygen barrier properties at high humidity were obtained [49].

\section{Thin Film Coatings and Multilayers}

As single layer biopolymer films rarely can meet the industrial requirements set for packaging, the thin film coatings or integrated multilayer structures are necessary.

\subsection{Sol-Gel}

Sol-gel coatings are ceramic or organically modified hybrid materials formed from a colloidal solution (sol) that acts as a precursor. Typical process involves the hydrolysis of alkoxysilanes to produce hydroxyl groups, followed by polycondensation among these groups and residual alkoxy groups to form a three-dimensional polymeric network (or gel). The sol-gel coatings have been applied onto base paper by spraying resulting in the coating amount of $2-5 \mathrm{~g} / \mathrm{m}^{2}$. Coatings with a longer alkyl chain were found to decrease the wettability and absorption of base paper more efficiently [50]. Sol-gel hybrid coatings applied with roll-to-roll pilot-line onto PLA laminated paperboard improved also other barrier properties [51]. In addition, the atmospheric plasma pretreatment has been used to activate PE-coated paper prior to applying the sol-gel coatings. Sol-gels functionalised with long-chain hydrocarbon groups or amino groups were sprayed and cured by drying at $110^{\circ} \mathrm{C}$. Hydrophobic coatings containing long hydrocarbon chains were effective barriers against grease penetration whereas hydrophilic coatings with amino groups reduced oxygen transmission rates especially at low relative humidity. Plasma activation clearly improved adhesion and performance of both coatings [52]. Also hexamethyldisiloxane has been utilized as a siloxane precursor for the atmospheric plasma deposition of hydrophobic siloxane coatings on LDPE-coated paper and board. However, only minor improvements were obtained in water vapour barrier properties [53].

\subsection{ALD}

Atomic layer deposition (ALD) technique is a surface-controlled layer-by-layer deposition process based on self-limiting gas-solid reactions. It is well suited to produce inorganic barrier coatings, such as $\mathrm{Al}_{2} \mathrm{O}_{3}, \mathrm{SiO}_{2}$ and $\mathrm{ZnO}$ on various materials including synthetic and biobased plastics and biopolymers such as PLA, PHB, pectin, galactoglucomannan and cellulose nanofibrils [54]-[57]. Atomic layer deposited $\mathrm{Al}_{2} \mathrm{O}_{3}$ has proven to be effective in enhancing the moisture and gas barrier properties of various films and coatings. With ALD ZnO coatings both barrier and antimicrobial properties of BOPLA and BOPP films were improved [58]. PLA films were coated with $20 \mathrm{~nm}$ polyelectrolyte multilayer film made from sodium alginate and chitosan and additionally with $25 \mathrm{~nm} \mathrm{ALD} \mathrm{Al}_{2} \mathrm{O}_{3}$ layer. The double-coating was found to significantly enhance the water vapour barrier properties of the PLA film due to increased surface hydrophobicity [59]. ALD, electron beam evaporation, magnetron sputtering and a sol-gel method have been used to deposit thin aluminum oxide coatings onto LDPE- and PLA-coated board. Increased barrier performance against moisture and oxygen permeation rates were observed with each technique. However, among the techniques tested ALD was found to be most suitable [60]. Typically ALD coatings have been produced with slow batch processes. Recently, 30 - $40 \mathrm{~nm} \mathrm{Al}_{2} \mathrm{O}_{3}$ barrier coatings were deposited onto cellophane, PLA and polyimide films with continuous roll-to-roll technique [61].

\subsection{Multilayers}

Based on the LCA analysis, the biobased multilayer coating consisting of starch, nanoclay and inorganic nanolayer has been found favourable in terms of $\mathrm{CO}_{2}$ emissions as compared to PET/aluminium coatings [62]. In some cases the individual biopolymer layers may even be attached to each other using biobased adhesives [63]. As single layer CNF films have relatively weak moisture resistance, flexibility and zero sealability, the multilayer structures have been recently produced. CNF was first dispersion coated onto PET film and further extrusion coated with LDPE resulting in a 3-layer structure. PET/CNF/LDPE film had excellent technical prop- 
erties which fulfilled both oxygen and water vapour barrier as well as sealability requirements of modified atmosphere food packaging. Demonstrator pouches filled with nitrogen were produced with the packaging machine and the oxygen concentration inside the packages was monitored as a function of time. As a result, CNF containing multilayer films performed better as compared to commercial 3-layer multilayer films containing EVOH barrier layer. The developed films could be used as a packaging material for dry or low moisture content food products such as dry snacks, dried fruits, nuts, spices etc. [64].

\section{Conclusion}

Current trends in the packaging industry are towards lighter weight materials for reduction of raw material use, transportation costs, and minimizing the amount of waste. Interest in sustainable materials combined with barrier improving fillers will continue to growth [1]. As single layer biopolymer films rarely have competitive edge against synthetic films, the combination of individual layers to multilayer structures is necessary. By multilayer structures the technical properties may be dramatically improved.

\section{References}

[1] Johansson, C., Bras, J., Mondragon, I., Nechita, P., Plackett, D., Simon, P., Gregor Svetec, D., Virtanen, S., Giacinti Baschetti, M., Breen, C., Clegg, F. and Aucejo, S. (2012) Renewable Fibers and Bio-Based Materials for Packaging Applications-A Review of Recent Developments. BioResources, 7, 2506-2552.

[2] Härkki, O., Karttunen, M., Kortet, S., Koponen, M. and Harlin, A. (2011) Biaxially Oriented PLA-MontmorilloniteNanocomposite for Barrier Film Applications. Nanocomposites 2011, Paris-Est, Creteil University, 6 p.

[3] Koivistoinen, O. (2013) Catabolism of Biomass-Derived Sugars in Fungi and Metabolic Engineering as a Tool for Organic Acid Production. Espoo, 43.

[4] Vartiainen, J., Tammelin, T., Pere, J., Tapper, U. and Harlin, A. (2010) Biohybrid Barrier Films from Fluidized Pectin and Nanoclay. Carbohydrate Polymers, 82, 989-996. http://dx.doi.org/10.1016/j.carbpol.2010.06.031

[5] Vartiainen, J., Kunnari, V. and Kokko, A. (2012) Bio-Hybrid Nanocomposite Roll-to-Roll Coatings for Fiber-Based Materials and Plastics. In: Thomas, S., et al., Eds., Natural Polymers, Biopolymers, Biomaterials, and Their Composites, Blends and IPNS, Advances in Materials Science, 2, 207-212.

[6] Matilainen, K., Harlin, A., Kunnari, V., Tammelin, T., Vartiainen, J., Pere, J., Vähä-Nissi, M., Mustonen, T., Hartman, J., Peltonen, S. and Härkönen, M. (2011) Up-Scaling Biohybrid Barrier Coating to Pilot Coater. International Workshop Safe Nanostructured Polymer Materials: Characterization and New Processing Technologies, Naples, 3-4 March 2011, 69.

[7] Forssell, P., Mikkilä, J., Moates, G. and Parker, R. (1997) Phase and Glass Transition Behaviour of Concentrated Barley Starch-Glycerol-Water Mixtures, a Model for Thermoplastic Starch. Carbohydrate Polymers, 34, 275-282. http://dx.doi.org/10.1016/S0144-8617(97)00133-1

[8] Forssell, P., Hulleman, S., Myllärinen, P., Moates, G. and Parker, R. (1999) Ageing of Rubbery Thermoplastic Barley and Oat Starches. Carbohydrate Polymers, 39, 43-51. http://dx.doi.org/10.1016/S0144-8617(98)00128-3

[9] Myllärinen, P., Buleon, A., Lahtinen, R. and Forssell, P. (2002) The Crystallinity of Amylose and Amylopectin Films. Carbohydrate Polymers, 48, 41-48. http://dx.doi.org/10.1016/S0144-8617(01)00208-9

[10] Shamekh, S., Myllärinen, P., Poutanen, K. and Forssell, P. (2002) Film Formation Properties of Potato Starch Hydrolysates. Starch-Stärke, 54, 20-24. http://dx.doi.org/10.1002/1521-379X(200201)54:1<20::AID-STAR20>3.0.CO;2-M

[11] Talja, R., Helén, H., Roos, Y. and Jouppila, K. (2007) Effect of Various Polyols and Polyol Contents on Physical and Mechanical Properties of Potato Starch-Based Films. Carbohydrate Polymers, 67, 288-295. http://dx.doi.org/10.1016/j.carbpol.2006.05.019

[12] Myllärinen, P., Partanen, R., Seppälä, J. and Forssell, P. (2002) Effect of Glycerol on Behaviour of Amylose and Amylopectin Films. Carbohydrate Polymers, 50, 355-361. http://dx.doi.org/10.1016/S0144-8617(02)00042-5

[13] Talja, R., Helén, H., Roos, Y. and Jouppila, K. (2008) Effect of Type and Content of Binary Polyol Mixtures on Physical and Mechanical Properties of Starch-Based Edible Films. Carbohydrate Polymers, 71, 269-276. http://dx.doi.org/10.1016/j.carbpol.2007.05.037

[14] Forssell, P., Lahtinen, R., Lahelin, M. and Myllärinen, P. (2002) Oxygen Permeability of Amylose and Amylopectin Films. Carbohydrate Polymers, 47, 125-129. http://dx.doi.org/10.1016/S0144-8617(01)00175-8

[15] Gaudin, S., Lourdin, D., Forssell, P. and Colonna, P. (2000) Antiplasticisation and Oxygen Permeability of StarchSorbitol Films. Carbohydrate Polymers, 43, 33-37. http://dx.doi.org/10.1016/S0144-8617(99)00206-4

[16] Myllymäki, O., Myllärinen, P., Forssell, P., Suortti, T., Lähteenkorva, K., Ahvenainen, R. and Poutanen, K. (1998) 
Mechanical and Permeability Properties of Biodegradable Extruded Starch/Polycaprolactone Films. Packaging Technology and Science, 11, 265-274. http://dx.doi.org/10.1002/(SICI)1099-1522(199811/12)11:6<265::AID-PTS438>3.0.CO;2-8

[17] Vartiainen, J. and Harlin, A. (2011) Crosslinking as an Efficient Tool for Decreasing Moisture Sensitivity of Biobased Nanocomposite Films. Materials Sciences and Applications, 2, 346-354. http://dx.doi.org/10.4236/msa.2011.25045

[18] Vartiainen, J., Tuominen, M. and Nättinen, K. (2010) Bio-Hybrid Nanocomposite Coatings from Sonicated Chitosan and Nanoclay. Journal of Applied Polymer Science, 116, 3638-3647.

[19] Vartiainen, J., Motion, R., Kulonen, H., Rättö, M., Skyttä, E. and Ahvenainen, R. (2004) Chitosan-Coated Paper: Effects of Nisin and Different Acids on the Antimicrobial Activity. Journal of Applied Polymer Science, 94, 986-993. http://dx.doi.org/10.1002/app.20701

[20] Vartiainen, J., Rättö, M., Tapper, U., Paulussen, S. and Hurme, E. (2005) Surface Modification of Atmospheric Plasma Activated BOPP by Immobilizing Chitosan. Polymer Bulletin, 54, 343-352.

[21] Vartiainen, J., Rättö, M., Lantto, R., Nättinen, K. and Hurme, E. (2008) Tyrosinase-Catalysed Grafting of Food-Grade Gallates to Chitosan: Surface Properties of Novel Functional Coatings. Packaging Technology and Science, 21, 317 328. http://dx.doi.org/10.1002/pts.813

[22] Hartman, J., Setälä, H., Laine, C., Anghelescu-Hakala, A., Matilainen, K., Hohenthal, C., Härkönen, M. and Harlin, A. (2013) Biobarrier Coatings for Fibre-Based Packaging. Proceedings of the 26th IAPRI Symposium of Packaging, Espoo, 10-13 June 2013, 210-219.

[23] Laine, C., Harlin, A., Hartman, J., Hyvärinen, S., Kammiovirta, K., Krogerus, B., Pajari, H., Rautkoski, H., Setälä, H., Sievänen, J., Uotila, J. and Vähä-Nissi, M. (2013) Hydroxyalkylated Xylans: Their Synthesis and Application in Coatings for Packaging and Paper. Industrial Crops and Products, 44, 692-704. http://dx.doi.org/10.1016/j.indcrop.2012.08.033

[24] Mikkonen, K., Laine, C., Kontro, I., Talja, R., Serimaa, R. and Tenkanen, M. (2014) Combination of Internal and External Plasticization of Hydroxypropylated Birch Xylan Tailors the Properties of Sustainable Barrier Films. Submitted to Green Chemistry.

[25] Talja, R., Kulomaa, T., Labafzadeh, S., Kyllönen, L., King, A., Kilpeläinen, I. and Poppius-Levlin, K. (2011) Cellulose Esters from Birch Kraft Pulps: New Biomaterials for Barrier Coating. 16th International Symposium on Wood, Fiber and Pulping Chemistry (16th ISWFPC), Vol. 2, Tianjin, 8-10 June 2011, 1394-1398.

[26] Labafzadeh, S., Kulomaa, T., Talja, R., Kyllönen, L., King, A., Poppius-Levlin, K. and Kilpeläinen, I. (2011) Fatty Acid Derivatives of Cellulose for Barrier Applications. Stockholm, Sweden: Innventia Ab. The 3rd Nordic Wood Biorefinery Conference, NWBC 2011, Stockholm, 22-24 March 2011, 250-252.

[27] Talja, R., Shan, J., Vähä-Nissi, M., King, A., Kilpeläinen, I. and Poppius-Levlin, K. (2010) A New Birch Xylan Derivative by Aqueous Benzylation. 11th European Workshop on Lignocellulosics and Pulp (EWLP), Hamburg, 16-18 August 2010, 403-406.

[28] Vuoti, S., Laatikainen, E., Heikkinen, H., Johansson, L.S., Saharinen, E. and Retulainen, E. (2013) Chemical Modification of Cellulosic Fibers for Better Convertibility in Packaging Applications. Carbohydrate Polymers, 96, 549-559. http://dx.doi.org/10.1016/j.carbpol.2012.07.053

[29] Talja, R., Clegg, F., Breen, C. and Poppius-Levlin, K. (2011) Nano Clay Reinforced Xylan Barriers. Stockholm, Sweden: Innventia Ab. The 3rd Nordic Wood Biorefinery Conference, NWBC 2011, Stockholm, 22-24 March 2011, 132 137.

[30] Hartman, J., Albertsson, A.C., Söderqvist Lindblad, M. and Sjöberg, J. (2006) Oxygen Barrier Materials from Renewable Sources: Material Properties of Softwood Hemicellulose-Based Films. Journal of Applied Polymer Science, 100, 2985-2991. http://dx.doi.org/10.1002/app.22958

[31] Hult, E.L., Ropponen, J., Poppius-Levlin, K., Ohra-Aho, T. and Tamminen, T. (2013) Enhancing the Barrier Properties of Paper Board by a Novel Lignin Coating. Industrial Crops and Products, 50, 694-700. http://dx.doi.org/10.1016/j.indcrop.2013.08.013

[32] Hult, E.L., Koivu, K., Asikkala, J., Ropponen, J., Wrigstedt, P., Sipilä, J. and Poppius-Levlin, K. (2013) Esterified Lignin Coating as Water Vapour and Oxygen Barrier for Fiber-Based Packaging. Holzforschung, 67, 899-905.

[33] Vartiainen, J. and Vikman, M. (2013) Health and Environmental Safety Aspects of CNF. Production and Applications of Cellulose Nanomaterials, Book Chapter. TAPPI, 57-58.

[34] Vartiainen, J., Pöhler, T., Sirola, K., Pylkkänen, L., Alenius, H., Hokkinen, J., Tapper, U., Lahtinen, P., Kapanen, A., Putkisto, K., Hiekkataipale, P., Eronen, P., Ruokolainen, J. and Laukkanen, A. (2011) Health and Environmental Safety Aspects of Friction Grinding and Spray Drying of Microfibrillated Cellulose. Cellulose, 18, 775-786. http://dx.doi.org/10.1007/s10570-011-9501-7 
[35] Vartiainen, J., Lahtinen, P., Kaljunen, T., Kunnari, V., Peresin, M.S. and Tammelin, T. (2014) Comparison of Properties between Cellulose Nanofibrils Made from Banana, Sugar Beet, Hemp, Softwood and Hardwood Pulps. 47th Pulp and Paper International Congress, Sao Paulo, 7-9 October 2014, 10.

[36] Spoljaric, S., Salminen, A., Luong, N., Lahtinen, P., Vartiainen, J., Tammelin, T. and Seppälä, J. (2013) Nanofibrillated Cellulose, Poly(Vinyl Alcohol), Montmorillonite Clay Hybrid Nanocomposites with Superior Barrier and Thermomechanical Properties. Polymer Composites, 35, 1117-1131.

[37] Vartiainen, J., Kaljunen, T., Kunnari, V., Lahtinen, P. and Tammelin, T. (2013) Large-Scale Production of CNF Films. Production and Applications of Cellulose Nanomaterials, Book Chapter. TAPPI, 239-240.

[38] Lahtinen, K., Nättinen, K. and Vartiainen, J. (2009) Influence of High-Temperature Heat Treatment on Barrier and Functional Properties of Polyolefin-Coated Papers. Polymer-Plastics Technology and Engineering, 48, 561-569. http://dx.doi.org/10.1080/03602550902824382

[39] Vartiainen, J., Kaljunen, T., Kunnari, V., Lahtinen, P., Salminen, A., Seppälä, J. and Tammelin, T. (2013) Nanocellulose Films: Towards Large Scale and Continuous Production. 26th IAPRI Symposium on Packaging, VTT, IAPRI, Espoo, 10-13 June 2013, 197-209.

[40] Juvonen, H., Smolander, M., Boer, H., Pere, J., Buchert, J. and Peltonen, J. (2011) Film Formation and Surface Properties of Enzymatically Crosslinked Casein Films. Journal of Applied Polymer Science, 119, 2205-2213. http://dx.doi.org/10.1002/app.32943

[41] Rämö, V., Anghelescu-Hakala, A., Nurmi, L., Mehtiö, T., Salomäki, E., Härkönen, M. and Harlin, A. (2012) Preparation of Aqueous Crosslinked Dispersions of Functionalized Poly(d,l-Lactic Acid) with a Thermomechanical Method. European Polymer Journal, 48, 1495-1503. http://dx.doi.org/10.1016/j.eurpolymj.2012.06.005

[42] Hartman, J., Albertsson, A.C. and Sjöberg, J. (2006) Surface- and Bulk-Modified Galactoglucomannan Hemicellulose Films and Film Laminates for Versatile Oxygen Barriers. Biomacromolecules, 7, 1983-1989. http://dx.doi.org/10.1021/bm060129m

[43] Saarikoski, E., Rautkoski, H., Rissanen, M., Hartman, J. and Seppälä, J. (2014) Cellulose/Acrylic Acid Copolymer Blends for Films and Coating Applications. Journal of Applied Polymer Science, 131, 40286-40295. http://dx.doi.org/10.1002/app.40286

[44] Saastamoinen, P., Mattinen, M., Hippi, U., Nousiainen, P., Sipilä, J., Lille, M., Suurnäkki, A. and Pere, J. (2012) Laccase Aided Modification of Nanofibrillated Cellulose with Dodecyl Gallate. BioResources, 7, 5749-5770.

[45] Österberg, M., Vartiainen, J., Lucenius, J., Hippi, U., Seppälä, J., Serimaa, R. and Laine, J. (2013) A Fast Method to Produce Strong NFC Films as a Platform for Barrier and Functional Materials. American Chemical Society, ACS Applied Materials and Interfaces, 5, 4640-4647. http://dx.doi.org/10.1021/am401046x

[46] Hult, E.L., Iotti, M. and Lenes, M. (2010) Efficient Approach to High Barrier Packaging Using Microfibrillar Cellulose and Shellac. Cellulose, Springer, 17, 575-586. http://dx.doi.org/10.1007/s10570-010-9408-8

[47] Peresin, M.S., Vartiainen, J., Kunnari, V., Kaljunen, T., Tammelin, T. and Qvintus, P. (2012) Large-Scale Nanofibrillated Cellulose Film: An Overview on Its Production, Properties, and Potential Applications. 4th International Conference of Pulping, Papermaking and Biotechnology, ICPPB 2012, Nanjing, 7-9 November 2012, Book of Abstracts.

[48] Virtanen, S., Vartiainen, J., Setälä, H., Tammelin, T. and Vuoti, S. (2014) Modified Nanofibrillated Cellulose-Polyvinyl Alcohol Films with Improved Mechanical Performance. The Royal Society of Chemistry, RSC Advances, 4, 1134311350. http://dx.doi.org/10.1039/c3ra46287k

[49] Lozhechnikova, A., Dax, D., Vartiainen, J., Willför, S., Xu, C. and Österberg, M. (2014) Modification of Nanofibrillated Cellulose Using Amphiphilic Block-Structured Galactoglucomannans. Carbohydrate Polymers, 110, $163-172$. http://dx.doi.org/10.1016/j.carbpol.2014.03.087

[50] Wang, S., Mahlberg, R., Nikkola, J., Mannila, J., Jämsä, S., Ritschkoff, A. and Peltonen, J. (2012) Surface Characteristics and Wetting Properties of Sol-Gel Coated Base Paper. Surface and Interface Analysis, 44, 539-547. http://dx.doi.org/10.1002/sia.3841

[51] Nikkola, J., Vartiainen, J., Vähä-Nissi, M. and Nättinen, K. (2013) Novel Packaging Materials Using Functional Thin Films and Coatings. European Coatings Conference-Packaging and Can Coatings, Düsseldorf, 11-12 June 2013, Vincentz Network GmbH \& Co.

[52] Nikkola, J. (2011) Raising the Barriers. European Coatings Journal, 41-47.

[53] Nättinen, K., Nikkola, J., Minkkinen, H., Heikkilä, P., Lavonen, J. and Tuominen, M. (2011) Reel-to-Reel Inline Atmospheric Plasma Deposition of Hydrophobic Coatings. Journal of Coatings Technology and Research, 8, 237-245. http://dx.doi.org/10.1007/s11998-010-9292-z

[54] Vähä-Nissi, M., Sundberg, P., Kauppi, E., Hirvikorpi, T., Sievänen, J., Sood, A., Karppinen, M. and Harlin, A. (2012) Barrier Properties of $\mathrm{Al}_{2} \mathrm{O}_{3}$ and Alucone Coatings and Nanolaminates on Flexible Biopolymer Films. Thin Solid Films, 520, 6780-6785. http://dx.doi.org/10.1016/j.tsf.2012.07.025 
[55] Hirvikorpi, T., Vähä-Nissi, M., Mustonen, T., Iiskola, E. and Karppinen, M. (2010) Atomic Layer Deposited Aluminum Oxide Barrier Coatings for Packaging Materials. Thin Solid Films, 518, 2654-2658. http://dx.doi.org/10.1016/j.tsf.2009.08.025

[56] Hirvikorpi, T., Vähä-Nissi, M., Nikkola, J., Harlin, A. and Karppinen, M. (2011) Thin $\mathrm{Al}_{2} \mathrm{O}_{3}$ Barrier Coatings onto Temperature-Sensitive Packaging Materials by Atomic Layer Deposition. Surface and Coatings Technology, 205, 5088-5092. http://dx.doi.org/10.1016/j.surfcoat.2011.05.017

[57] Hirvikorpi, T., Vähä-Nissi, M., Harlin, A., Marles, J., Miikkulainen, V. and Karppinen, M. (2010) Effect of Corona Pre-Treatment on the Performance of Gas Barrier Layers Applied by Atomic Layer Deposition onto Polymer Coated Paperboard. Applied Surface Science, 257, 736-740. http://dx.doi.org/10.1016/j.apsusc.2010.07.051

[58] Vähä-Nissi, M., Pitkänen, M., Salo, E., Kenttä, E., Tanskanen, A., Sajavaara, T., Putkonen, M., Sievänen, J., Sneck, A., Rättö, M., Karppinen, M. and Harlin, A. (2014) Antibacterial and Barrier Properties of Oriented Polymer Films with ZnO Thin Films Applied with Atomic Layer Deposition at Low Temperatures. Thin Solid Films, 562, 331-337.

[59] Hirvikorpi, T., Vähä-Nissi, M., Harlin, A., Salomäki, M., Areva, S., Korhonen, J. and Karppinen, M. (2011) Enhanced Water Vapour Barrier Properties for Biopolymer Films by Polyelectrolyte Multilayer and Atomic Layer Deposited $\mathrm{Al}_{2} \mathrm{O}_{3}$ Double-Coating. Applied Surface Science, 257, 9451-9454.

[60] Hirvikorpi, T., Vähä-Nissi, M., Harlin, A. and Karppinen, M. (2010) Comparison of Some Coating Techniques to Fabricate Barrier Layers on Packaging Materials. Thin Solid Films, 518, 5463-5466. http://dx.doi.org/10.1016/j.tsf.2010.04.018

[61] Hirvikorpi, T., Laine, R., Vähä-Nissi, M., Kilpi, V., Salo, E., Lia, W.M., Lindfors, S., Vartiainen, J., Kenttä, E., Nikkola, J., Harlin, A. and Kostamo, J. (2013) Barrier Properties of Plastic Films Coated with an $\mathrm{Al}_{2} \mathrm{O}_{3}$ Layer by Roll-toRoll Atomic Layer Deposition. Thin Solid Films, 550, 164-169.

[62] Hohenthal, C. and Veuro, S. (2011) The Role of LCA in Guiding Projects. FlexPakRenew Workshop, Lyon, 10 May 2011.

[63] Hult Mori, E.L. (2012) Bio-Based Adhesives Packaging. In: Sundqvist, H., Ed., Research Highlights in Industrial Biomaterials, VTT Research Highlights, VTT, Espoo, No. 2, 79-81.

[64] Vartiainen, J., Kaljunen, T., Nykänen, H., Malm, T. and Tammelin, T. (2014) Improving Multilayer Packaging Performance with Nanocellulose Barrier Layer. TAPPI Place Conference 2014, Ponte Vedra, 13-15 May 2014, 5. 
Scientific Research Publishing (SCIRP) is one of the largest Open Access journal publishers. It is currently publishing more than 200 open access, online, peer-reviewed journals covering a wide range of academic disciplines. SCIRP serves the worldwide academic communities and contributes to the progress and application of science with its publication.

Other selected journals from SCIRP are listed as below. Submit your manuscript to us via either submit@scirp.org or Online Submission Portal.
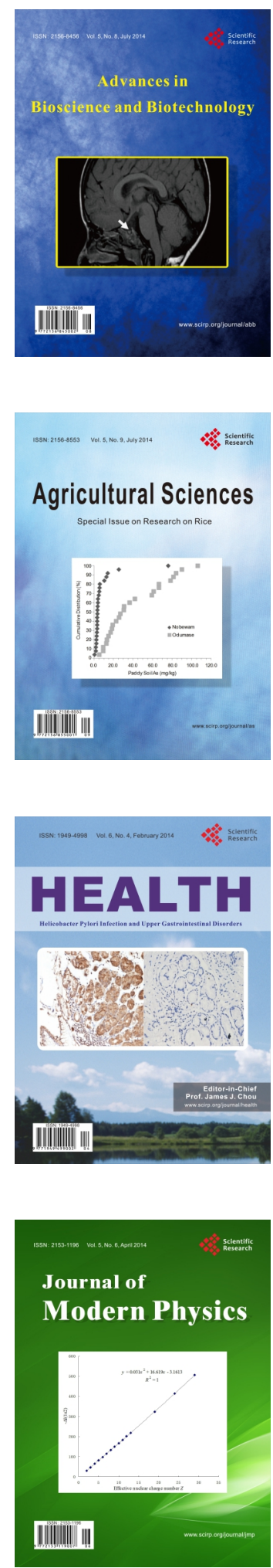
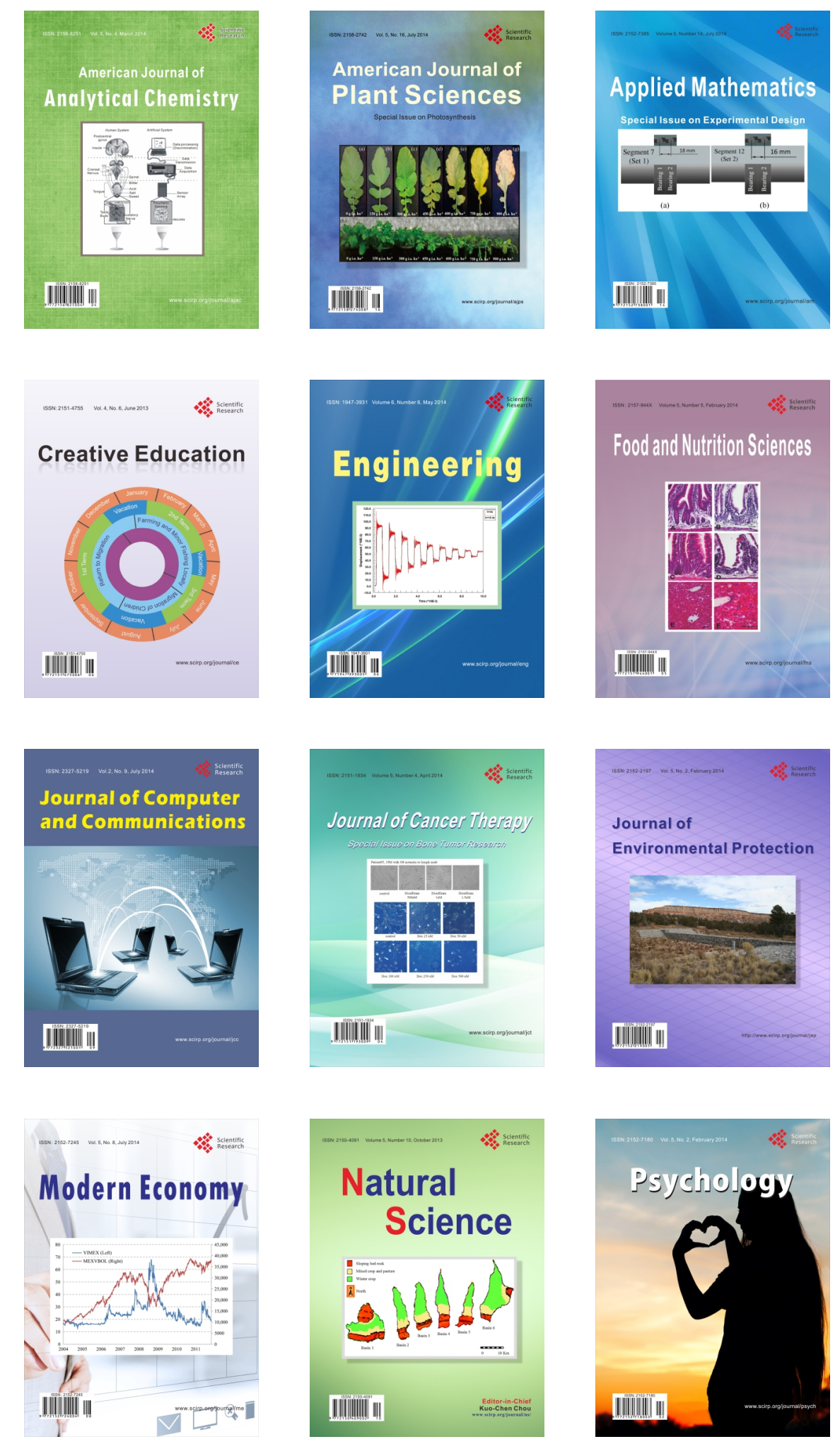